\title{
AVALIAÇÃO DA MORTALIDADE INFANTOJUVENIL POR LINFOMA NÃO HODGKIN NO BRASIL
}

\author{
Filipe Rolim Medeiros ${ }^{l}$, Maria Mirelle Ferreira Leite Barbosa ${ }^{1}$, Daniela Matos Carneiro ${ }^{1}$, \\ Inêz Gabrielle Duarte Sousa ${ }^{1}$, Francisco Davi Gomes Araújo ${ }^{1}$, Flaviana Ferreira de Oliveira ${ }^{1}$, \\ Millene Ivania Ferreira Leite Barbosa².
}

Introdução: As neoplasias mais frequentes entre crianças e adolescentes são as leucemias, os tumores do sistema nervoso central e os linfomas. Os linfomas não-Hodgkin que ocorrem nas crianças correspondem a um grupo heterogêneo com diversos tipos histológicos, sendo mais comum o tipo Burkitt. Segundo dados do Instituto Nacional de Câncer (INCA), a taxa de mortalidade geral por linfoma não-Hodgkin cresceu 17\% entre 2004 e 2013 (último dado disponível). Objetivo: Avaliar os índices de mortalidade por Linfoma nãoHodgkin em crianças e adolescentes (0 a 19 anos), no Brasil, entre 2009 e 2013. Método: Foi realizado um estudo quantitativo, descritivo, transversal, baseado em dados secundários do Ministério da Saúde e do INCA sobre casos de óbito por Linfoma não-Hodgkin, em todas as regiões do Brasil, entre os anos de 2009 e 2013. Resultados: A taxa de mortalidade média ajustada por idade para o Brasil foi de 2,70 por milhão de crianças e adolescentes no período analisado. Essa taxa foi mais expressiva no sexo masculino (3,66 óbitos por milhão) quando comparado ao feminino (1,70). A faixa etária com maior índice de mortalidade foi a de 15 a 19 anos, em ambos os sexos, com taxa de 4,45. Entre as regiões do país, as que apresentaram maiores taxas foram a Região Sul e a Nordeste (três por milhão), e as menores, Regiões Norte e Sudeste (2,50 por milhão). Conclusão: Neste estudo foi observado um maior risco de morte por Linfoma nãoHodgkin para crianças do sexo masculino, com idade entre 15 a 19 anos, além de residentes nas Regiões Sul e Nordeste do país. Sendo assim, é possível denotar que a faixa etária infantojuvenil possui taxa de prevalência que reflete o cenário brasileiro em que está inserida. Em suma, é possível observar a importância da análise das tendências de mortalidade por esse tipo de neoplasia hematológica, pois a mesma pode fornecer subsídios para avaliação de estratégias de detecção precoce voltadas para o grupo infantojuvenil.

Palavras-chaves: Infantojuvenil; Linfoma Não-Hodgkin; Mortalidade.

\footnotetext{
${ }^{1}$ Acadêmico de Medicina em Faculdade de Medicina Estácio de Juazeiro do Norte - ESTÁCIO FMJ;

${ }^{2}$ Cirurgiã Geral formada pelo Hospital Getúlio Vargas - HGV - Recife (PE);

Autor correspondente: filipe_rm89@hotmail.com.
}

19 Id on Line Rev. Mult. Psic. V.12, N. 40. 2018 - ISSN 1981-1179 EDIÇÃO ESPECIAL: I CURSO DE ONCOLOGIA DO CARIRI / II JORNADA DE PESQUISA QUANTI-QUALITATIVA EM ONCOLOGIA. JUAZEIRO DO NORTE, 05 A 10 DE MARÇO DE 2018. Edição eletrônica em http://idonline.emnuvens.com.br/id 